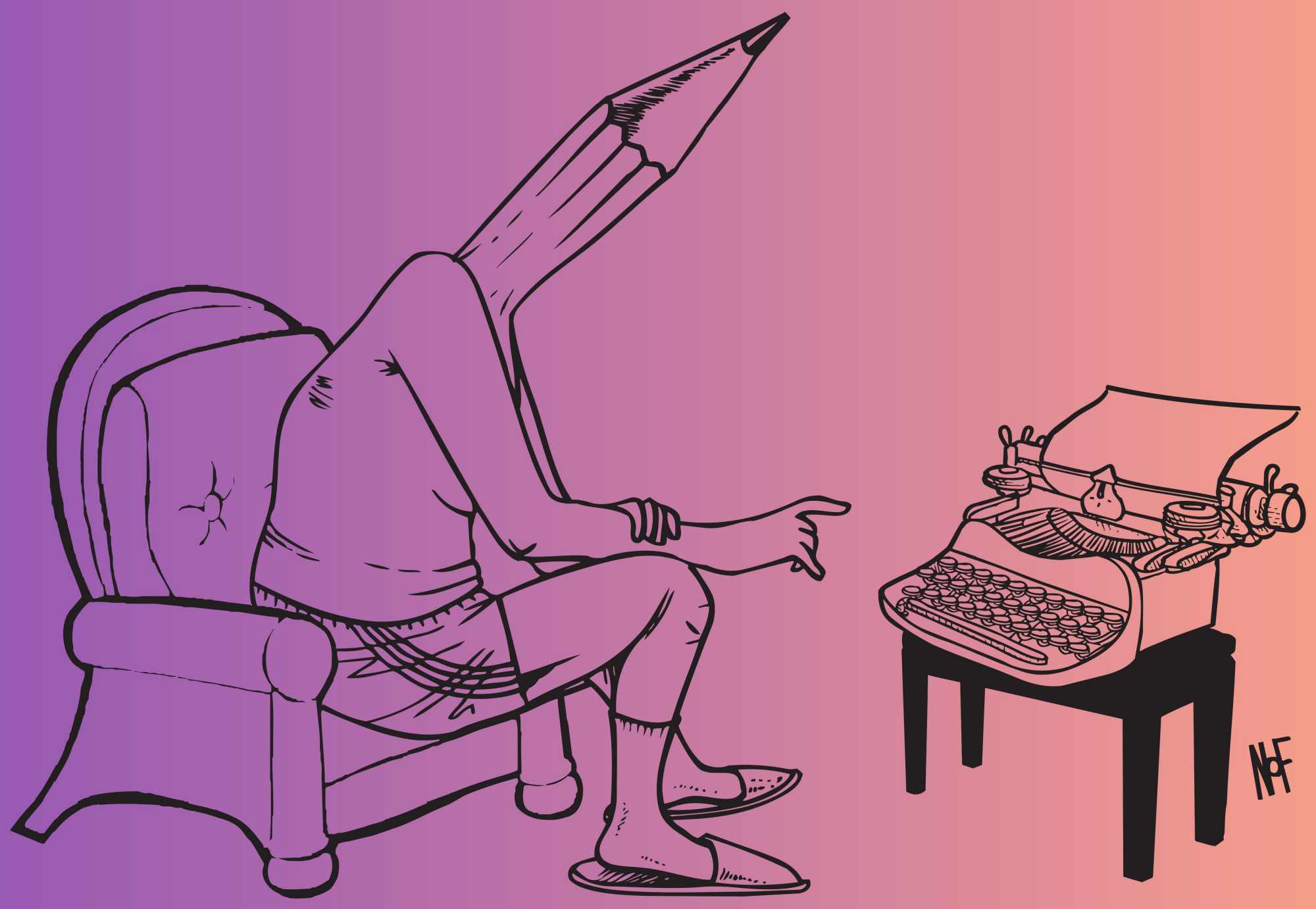




\section{El caso Karina del Pozo}

\section{Estefanía Montalvo, Rafael Castro y Pamela Gaon*}

Fecha entrega: 2014-03-10 • Fecha aprobación: 2014-04-10

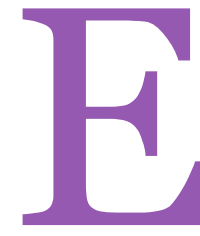

l presente artículo trata acerca de cómo reaccionó la opinión pública en el caso de la desaparición y posterior muerte de Karina del Pozo. Las primeras versiones del hecho estaban enfocadas hacia un tema de inseguridad ciudadana. Luego, se confirmó que los asesinos eran sus propios amigos. 
Es necesario partir de un resumen cronológico de los eventos ocurridos entre el miércoles 20 de febrero (fecha en la cual se difunde el primer mensaje de alerta por la desaparición de la joven) y el sábado 18 de mayo (día en el cual los familiares de la víctima realizan la última marcha en repudio contra la violencia de género y en solidaridad con los familiares de las personas desaparecidas).

En este lapso de tiempo se generán diversas reacciones en los medios de comunicación, así como en la opinión pública manifestada a través de la red social Facebook.

En una primera instancia, el debate es direccionado a la delincuencia común; luego, se habla más de las relaciones interpersonales para, finalmente, generar un debate sobre la violencia de género y femicidio. Este caso empieza con un anuncio publicado en la red social Facebook, el 20 de febrero de 2013. En él aparecía la foto de una mujer joven acompañada del siguiente texto:

\section{"AYÚDANOS A ENCONTRARLA}

Su nombre es Karina del Pozo Mosquera, tiene 20 años, se la vio por última vez tomando un taxi en la Mariano Echevarria y Av. Brasil el día miércoles 20 de febrero a las zam apróximadamente (en la madrugada). Desde ese día NADIE sabe nada de ella, y su celular esta apagado iSU FAMILIA ESTÁ DESESPERADA!"

El mensaje estaba acompañado de los teléfonos de contacto así como de una recomendación "difunde esta imagen para encontrarla". Muy pronto, el mensaje se viralizó, al punto que esta desaparición, una entre muchas, se convirtió en tema de discusión local, saltando desde las redes sociales hasta los medios de comunicación y, final- mente, haciendo que las autoridades se pronunciaran al respecto.

Durante los primeros 7 días, después de publicado el mensaje, el caso de la mujer desaparecida se convirtió en el símbolo de la lucha ciudadana contra la delincuencia. La joven huérfana, desde los trece años, modelo eventual, universitaria, que esa tarde estaba entregando hojas de vida para conseguir un trabajo fijo, cautivaba a la opinión pública, quienes se manifestaban en las redes sociales dando su voz de apoyo a la familia, elevando plegarias o, en una gran mayoría de los casos, quejándose de la administración gubernamental en la cual el debate sobre la delincuencia era un tema recurrente. El caso de Karina del Pozo fue la gota que derramó la copa de la paciencia ciudadana.

El día 27 de febrero, José Serrano, ministro de Interior, publicaba en la red social Twitter el siguiente mensaje:

Ministro @ppsesa informa el hallazgo del cuerpo de Karina del Pozo, joven desaparecida hace 10 días en Quito. Hay tres detenidos.

\section{El anuncio hecho desde el} Ministerio del Interior se comEl caso plementaba con la información de que los presuntos asesinos serían los propios amigos y que la versión del taxi era una maniobra distractora para desviar la atención de las autoridades. En este punto, la opinión pública y los medios de comunicación se redireccionan hacia dos vertientes: por un contra la delincuencia. lado, ya no se hablaba de la delincuencia común sino de los femicidios; y, por otro, existía una preocupación general (especialmente desde los padres de familia) acerca de la importancia de elegir bien las amistades.

En el mes de marzo, los medios recojen versiones de los testimonios de 


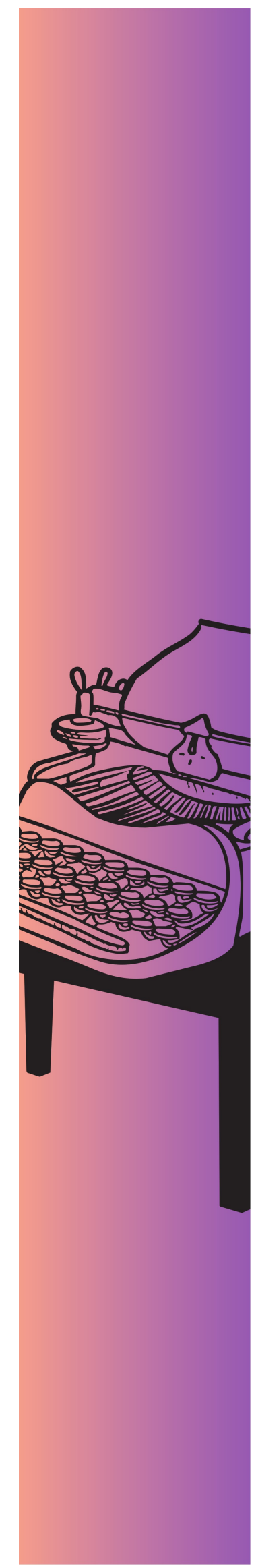

los presuntos asesinos, la reacción de los familiares y las marchas de estos, en compañía de familiares de desaparecidos con fines diversos y con pocos asistentes en relación a las manifestaciones de apoyo realizadas a través de las redes sociales.

Finalmente, la Asamblea Nacional deja en el aire la idea de hacer la Ley Karina del Pozo , cuyo objetivo es castigar más severamente a los femicidas.

\section{Preámbulo}

El caso Karina del Pozo cuenta con tres instancias:

1. La desaparición: el llamado desde las redes sociales, la primera hipótesis del rapto efectuado por un taxista; al parecer, un caso de delincuencia común. Esta étapa duro 7 días, del 20 al 27 de febrero.

2. El esclarecimiento de el crimen: las autoridades dan con los responsables. Las discusiones sobre el tema pasan de la delincuencia común a los delitos de género. Esta étapa comprende desde el 27 de febrero (publicación de el tuit del Ministro de Interior) hasta el 3 de abril (día en el cual, basados en los testimonios de los asesinos, la Fiscalía encuentra la piedra con la que se efectuó el crimen).

3. La manifestación: los familiares marchan con fines diversos y las autoridades buscan canalizar a través de leyes, la inconformidad coyuntural de la opinión pública creando la Ley Karina del Pozo. Esta fase está comprendida entre el 3 de abril y el 18 de mayo (fecha de la última marcha).

Para entender el proceso de configuración de la opinión pública en este caso, es oportuno citar a Vincent Price, quien menciona las fases de la formación de la opinión pública:

1. Fase problema: una situación se determina como problemática por una persona particular.

2. Fase propositiva: se plantean líneas potenciales de decisión. Formas de resolverlos.

3. Fase política: debate de méritos y debilidades de las alternativas (discurso público-encuestadores).

4. Fase del Programa: plan de acción, ejecutar, curso de acción.

5. Fase de evaluación: evaluaciones de la efectividad de la política por las minorías no muy convencidas.

Es importante recalcar que la fase problema muta entre las instancias 1 y 2 del caso; se pasa de un tema de delincuencia común a uno de violencia de género. La fase propositiva es emitida desde el Ejecutivo 
ante la falta de propuestas claras vertidas desde los espacios de manifestación de la opinión pública. Tres meses y medio después del asesinato, no se tenía un bosquejo claro de cómo sería la Ley Karina del Pozo. La respuesta del Ejecutivo obedecía a una acción estrictamente coyuntural que buscaba canalizar políticamente el malestar ciudadano, o, en el mejor de los casos, se vio interrumpido por el cambio de representantes en la Asamblea Nacional. A pesar de que se está en un proceso embrionario de la formación de la opinión pública, según las categorías de Vincent Price, consideramos importante el análisis de las instancias desde el pensamiento de Bourdieau y Bauman.

A su vez llama la atención la participación de una parte de la ciudadanía a través de las redes sociales, al momento de realizar un análisis sobre la construcción de conceptos alrededor de la opinión pública y la configuración de nuevos canales y medios que dan poder a sus opiniones. Se puede decir que esta reconfiguración obliga a releer a Vincent Price cuando habla de masa, multitud y público o cuando se refiere a los lugares de configuración de la opinión pública.

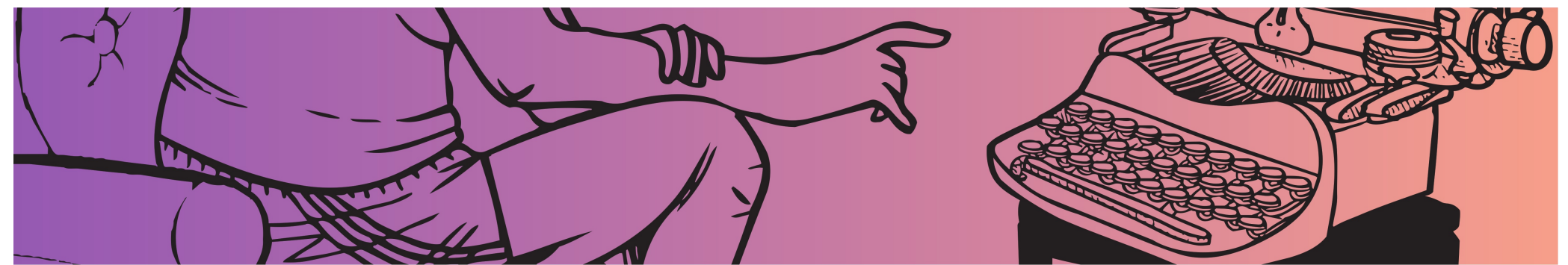

\section{Desarrollo}

\section{La desaparición.}

Paralelo a la publicación de los mensajes en busca de Karina del Pozo, la opinión pública se manifestaba en las redes sociales buscando culpables, o por lo menos, catalogando categorías de culpables. Pese a que las primeras versiones hablaban de un "taxi amarillo", el enemigo común no tenía forma, era etéreo y, como tal, se le debía ubicar, delimitar y, en suma, encuadrar el problema. Parafraseando a Bauman "... siempre que el disenso se presenta difusamente y no focalizado, y que reinan la sospecha mutúa y la hostilidad, la única manera de alcanzar o recuperar la solidaridad comunitaria y el hábitat seguro -por solidario- es la elección de un enemigo común...” (Bauman, 1999, p. 24).

La búsqueda de culpables (enemigo común) por parte de la opinión pública en redes sociales fue particularmente efectiva, evidenciada en mensajes como estos:

\footnotetext{
“Juan Ojeda: Eso es culpa del gobierno, que sigue abriendo fronteras y dice que en el país no pasa nada. Qué les cuesta pedir visa, hasta cuando...”.

"Darío Castellanos Barrera: El alcalde burro sólo se preocupa del aeropuerto y la delincuencia ahí está. Hasta cuándo Barrera”.

"Andrea Yépez: Malditos ladrones deben morirse todos".

"Matho Zebas Ldu: Las autoridades no sirven en este país. Otro caso que quedará en la impunidad".
}

Pese a que aún no existía una hipótesis clara acerca de los motivos del crimen, las opiniones del público juzgaban a los gobernantes por no proteger a la población ante la delincuencia común (en algunos casos extranjera), o, incluso, de la 
"laxitud" del sistema penal. En ese sentido, se hizo bastante común la reacción violenta ante la violencia. Se pedía, obviando cualquier consideración jurídica, la implementación de la pena de muerte, el derecho a la autodefensa e, incluso, se juzgaba a aquellos que participaban en el sistema jurídico o en la defensa de los derechos humanos.

"María del Carmén Taboada: Estos cerdos deberían ser colgados en plazas públicas $\mathrm{y}$ pagar por lo que hacen. Seguro Dios estaría muy de acuerdo".

"Andrés Logacho Torres: y según el dictador y sus borregos "SON TIEMPOS DIFÍCILES PARA LA DELINCUENCIA". En vez de comprarme un nuevo Samsung Galaxy me compraré una AK 47, no queda más!!!”

"Good Gers: por mí, esos de los derechos humanos se pueden ir a la mismísima gaver a eso desgraciados deberían ahorcarlos o quemarlos enfrente de todos para que esos desgraciados no vuelvan hacerlo".

La indignación colectiva y la búsqueda de enemigos comunes es, a decir de Bauman, un acto que recupera la solidaridad comunal; incluso, desde ese marco es entendible la reacción violenta:

\footnotetext{
"Solo la comunidad de cómplices puede garantizar (mientras dura) que el crimen no sea llamado crimen y castigado como tal. Por lo tanto, la comunidad no tolerará fácilmente a las personas que se nieguen a unirse al tumulto general, ya que esa negativa pone en duda la justicia misma del acto" (Bauman, 1999, p. 24).
}

¿Por qué este caso en especial provocó estas reacciones? Esbozando una respuesta tentativa se deben tomar en cuenta dos vertientes. Por un lado, la víctima: una mujer joven, guapa, huérfana, que buscaba trabajo, de clase media, universitaria, etc. La condición de joven caída en desgracia, sus deseos de sobreponerse a las adversidades, una especie de heroína para el colectivo; una chica, que a pesar de todo, aparecía coqueta y sencilla en las fotografías que subieron sus amigos y familiares en las redes sociales. La sensación de la belleza idealizada y vulnerada por un enemigo silencioso, etéreo, omnipresente.... Por otro lado, cabe citar, de nuevo, a Bauman y su percepción del mundo contemporáneo:

categorias "El mundo contemporáneo es e culpables un container lleno hasta el borde del miedo y la desesperación flotantes, que buscan desesperadamente una salida. La vida está sobresaturada de aprensiones oscuras y premoniciones siniestras, aún más aterradoras por su inespecificidad, sus contornos difusos y sus raíces ocultas. Como en el caso de otras soluciones sobresaturadas, una mota de polvo -Sidney Cooke, por ejemplo- es suficiente para provocar una violenta condensación" (Bauman, 1999, p. 23).

Mientras las investigaciones por el caso del Pozo avanzaban, se esclarece que quienes realmente fueron los culpables de su muerte, eran sus propios amigos. En este escenario da un giro la noción que tenía la ciudadanía respecto a la inseguridad en las calles; ahora se vuelve un tema más privado, que devuelve la responsabilidad a los padres de familia, a los centros educativos, y demás entes encargados de la edificación moral y ética de los ciudadanos.

\section{El esclarecimiento del crimen.}

El encuentro de los asesinos de Karina del Pozo, su posterior testimonio y el tratamiento que a esta información se le dio en los medios (especialmente en 
El Telegrafo) fomenta en la opinión pública dos tipos de culpables: 'ellos' (los asesinos) y 'ella' (quien no supo elegir adecuadamente sus amistades).

\section{Los sospechosos}

Son tres (uno de ellos es experto en artes marciales) y presentan antecedentes de violencia callejera. El público pide que sean castigados con severidad. El caso está en el punto en el que se encuentran las preocupaciones privadas (la vulnerabilidad de las hijas, hermanas, amigas) con los temas de debate públicos (la inseguridad, la descomposición social y más). Se hayan similitudes en la reacción con el caso Cooke, referenciado anteriormente por Bauman; el autor se refiere de esta manera:

\footnotetext{
"Primero, Cooke está catalogado: esa calificación lo convierte en un blanco tangible y lo extrae del conglomerado de miedos ambientales confiriéndole una realidad corporal que otros temores no poseen; aún cuando no se lo vea, es posible percibirlo como un objeto sólido que puede ser dominado, esposado, encerrado, neutralizado y hasta destruido, a diferencia de la mayoría de las amenazas, que tienden a ser descocertantemente difusas, vagas, evasivas, invasoras, inidentificables. Segundo, por una feliz coincidencia, Cooke ha sido puesto en el lugar en que se cruzan las preocupaciones privadas y los temas públicos; más precisamente, su caso es como un crisol alquímico en el que el amor por los hijos -una experiencia cotidiana, rutinaria, pero privada- puede transustanciarse de manera milagrosa en un espectáculo público de solidaridad. Y en última instancia, pero no menos importante, la situación es un puente suficientemente ancho como para permitir que un grupo -tal vez muy numerosoencuentre una vía de escape; cada evadido solitario se topa allí con otra gente que está huyendo de su propia prisión privada, y de este modo se crea una comunidad a partir del solo hecho de emplear la misma ruta de escape, que seguirá existiendo mientras hayan pies que la recorran" (Bauman, 1999, p. 19).
}

De otro lado, desde la perspectiva de una sociedad patriarcal, comienza un lento proceso de desmitificación de la víctima. Esto ayudado desde los medios de comunicación oficiales quienes parecian tener como fin el deslindar cualquier tipo de responsabilidad del Estado.

Los tipos de opiniones que se generaban en la opinión pública giraban en torno a dos ejes: el endurecimiento de las penas para los victimarios y la responsabilidad que deben asumir las mujeres al estar en la calle a altas horas de la noche. Por un lado, existía un sentimiento de justicia colectiva del tipo "ojo por ojo" en lo público; y, por otro lado, se fomentaba un sentimiento paternalista -patriarcal- en el núcleo familiar -lo privado-.

Bourdieau podría interpretar esta ambigüedad de la siguiente manera:

En suma, la proposición "las clases populares son represivas" no es verdadera ni falsa. Es verdadera en la medida en que, ante todo un conjunto de problemas como los que atañen a la moral doméstica, a las relaciones entre generaciones o entre sexos, las clases populares tienen tendencia a mostrarse mucho más rigo- 
ristas que las otras clases sociales. Por el contrario, en las custiones de estructura política, que ponen en juego la conservación o transformación de los modos de relación entre los individuos, las clases populares son mucho más partidarias a la innovación, es decir, de una transformación de las estructuras sociales (Bourdieu, 1972, p. 4).

La culpable

A mediados del mes de marzo de 2013, se podían leer comentarios como los siguientes:

"Leandro BSC: Cada quién busca su destino, nadie le manda a subirse a la camioneta. La culpa es de ella y de nadie más..! tampoco es que ella era una santa paloma ..."

"Pablo Germán Vaca Torres: PADRES DE FAMILIA verán con la clase de individuos salen sus hijas a escondidas a moteles de mala muerte con esos individuos regaytonerosii”

"Jaime Solís: Chicas.... aprendan a escoger a sus verdaderos amigos.. ojo"

En ese sentido, Nancy Fraser señala que:

"La exacerbación del sexismo es característico de la nueva esfera pública: nuevas normas de género que insistieron en la domesticidad femenina y una separación tajante de esferas públicas y privadas funcionaron como códigos y significados de una diferencia burguesa que la separó de los estratos sociales superiores e inferiores. Es un claro indicador del éxito de este proyecto burgués el hecho que las mismas normas llegaron posteriormente a ser hegemónicas, ahora impuestos sobre, y ahora acogidos por, segmentos más amplios de la sociedad”.

(Fraser, 1991).

Basado en el tema de las sociedades patriarcales, el diario público (por no decirlo oficial) El Telégrafo realizó el cubrimiento de la muerte de Karina del Pozo, cuyo fin fue el de construir sentidos enfocados a cuidar el buen nombre del Gobierno en la lucha contra la delincuencia. Las 113 noticias, que publicó este diario entre el 20 de febrero del 2013, fecha en la que se denunció la desaparición de Karina del Pozo y el 20 de abril, cuando se emitió el dictamen acusatorio dentro del proceso en la Fiscalía, fueron enfocadas a denotar una anomalía de comportamientos de los presuntos responsables. Se construyó una campaña para convencer a los jóvenes de que deben cambiar de hábitos y evitar los riesgos. Es decir, hablaban del consumo de licor, de la posible ingesta de drogas en las declaraciones de los implicados, etc.

Este discurso se articuló con la idea gubernamental, incluso a nivel editorial, de que los adolescentes deben tener precaución, deben evitar tomar alcohol en exceso y más. No bastó para el Gobierno utilizar la plataforma de El Télégrafo para lograr sembrar esa idea en la opinión pública sino que utilizó otras plataformas para ahondar con un concepto moralista. La Secretaría Nacional de Comunicación, pautó un 'spot' del Gobierno contra del abuso del alcohol en

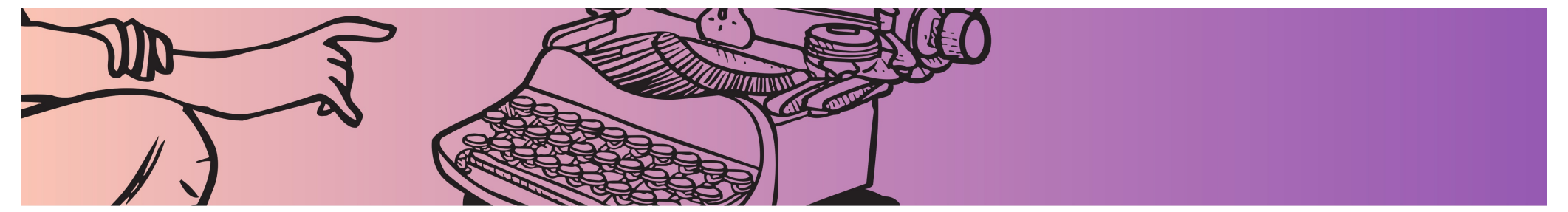


los jóvenes. La cuña mostraba a una adolescente en estado de embriaguez que al final se sube en el auto de unos desconocidos. La idea supuestamente fue concienciar a las personas sobre los "peligros" de "perder el control de tu vida" a causa del alcohol. Sin embargo, el 'spot' fue muy cuestionado, lo que obligó a retirarlo del aire. Surge la duda natural acerca de si el comercial obedecía a la lógica "moralista" coyuntural del Gobierno o de si se trataba de una infeliz coincidencia.

Una vez que se retiró del aire el 'spot', el Ministerio del Interior difundió un comunicado en el que contaba lo que hacían para reducir la violencia de género. El ministro del Interior, José Serrano, hizo un plan de medios para decir que el crimen de Karina del Pozo no quedará en la impunidad. El Telégrafo lo editorializó, le dio páginas completas a este discurso oficial.

El artículo de Rocío Carpio, con el título Todo lo que te pasa es por tu culpa, por puta, es revelador en cuanto a la construcción que hizo el Gobierno del concepto de violencia y de inseguridad. En ese sentido, Carpio dice:

\begin{abstract}
"El riesgo precisamente es ese. Al traducir una dinámica social y trasladarla al plano mediático, que por fuerza, cobra una lógica alegórica, estamos frente a lo que Bourdieu llamó "violencia simbólica”, que entre otras cosas, describe la reproducción del dominio masculino sobre las mujeres. Y aún este spot (el mencionado spot de la SECOM) va más allá del concepto de violencia simbólica, en el sentido de que esa violencia invisible de la que habla Bordieu está siendo evidenciada pero no a modo de denuncia, sino por el contrario, a manera de naturalización del comportamiento masculino y estigmatización del comportamiento femenino" (Carpio, 2013).
\end{abstract}

El Telégrafo publicó títulos como:

\begin{abstract}
"Karina del Pozo intentó defenderse antes de que la asesinaran”, "Dos detenidos relataron cómo asesinaron a Karina del Pozo”, "Autores se lavaron la sangre con licor luego del crimen”,

"Una botella de ron fue el pretexto para seguir la "farra". Jamás en sus titulares, notas ni artículos de opinión, cuestionaron el rol del Estado en la seguridad y el bienestar de los ciudadanos, sino que construyeron una idea sobre el consumo del licor y la culpa que tienen las jóvenes de exponerse a este tipo de peligros.
\end{abstract}

Es importante citar la hipótesis principal del estudio realizado por Rosanna Reguillo quien concluye que: "Aquel que controle los miedos y contenga las esperanzas dominará el proyecto social del siglo XXI” (Reguillo, 1998). El debate fue disperso, pero el enfoque que dio El Telégrafo fue el de librar de culpa al Gobierno y condenar ciertas conductas de la juventud con una visión extremadamente conservadora.

Reguillo, refiriéndose a los miedos, resalta que:

"Los temores finiseculares, algunos objetivos (el aumento de la delincuencia, las expresiones diversas de la violencia, el deterioro ambiental, la falta de empleos, etc.) y otros más producto de ideologías de clase o de grupo (el temor a los homosexuales, a "los pobres" como directamente responsables de los males que aquejan a las sociedades, por ejemplo), están vinculados a un sistema de creencias que hoy se ve tensionado por la existencia de unos medios de comunicación globalizados, que al tiempo que se alimentan del acontecer, proponen claves de lectura de la realidad, operando una mediación que fortalece o debilita el significado propuesto en función de la interacción cara a cara y la experiencia directa, que configura ámbitos de representación e interpretación en virtud de las diferentes identidades sociales en el espacio público, ancladas en matrices socioculturales. Desde estas matrices culturales se elaboran 
discursos construidos, cuya función es elaborar una "explicación" plausible del mundo, en relación a los miedos y a las alternativas que cada grupo portador elabora en forma de representaciones para la acción y que nutren a las identidades sociales, al reingresar (en relación al grado de poder implicado) al acervo colectivo -globalizado- por la mediación tecnológica” .

En las noticias de El Telégrafo, los términos que están asociados al caso de Karina del Pozo giran en torno al relato de los hechos del día de su muerte. Qué pasó antes, dónde estuvo, qué tomó, qué hizo, el consumo de alcohol, entre otros. El objetivo es escandalizar a sus lectores pero a la vez ahondar en el imaginario de la violencia de género, con una visión muy particular. Jamás se cuestiona, por ejemplo, la impunidad de otras decenas de casos similares a los de Karina del Pozo que se redujeron a notas pequeñas, que no tienen ni seguimiento ni peso.

Para Sigmund Bauman, "el bien común, está siendo comido por los políticos ambiciosos y por los ciudadanos cobardes, la representatividad está muerta, parece ser que la vida pública ahora es exigir que lo público sea trasladado de nueva cuenta a los espacios públicos, no a un grupo específico o de intereses singulares" (Bauman, 2001). Pero la pregunta es ¿quién o qué determina que un caso se vuelva público y otro no? La actuación de un actor fundamental, el Gobierno. En este caso, el tema se volvió político, desde el día que José Serrano, ministro del Interior, intervino en él. Fue la plataforma perfecta para impulsar su imagen y a la vez la del Gobierno. En esta estrategia, El Telégrafo y otros medios públicos y oficiales cumplieron un papel fundamental. Trabajaron con ese norte.

\section{La manifestación}

El 18 de mayo de 2013, se realizó la última marcha relacionada con el caso Karina del Pozo. El objetivo era el de pedir justicia por este y por otros casos de personas desaparecidas y abusadas. La marcha citada en la Cruz del Papá del Parque La Carolina, no contó con una gran afluencia de manifestantes, tampoco con un cubrimiento destacado de los medios. Las últimas noticias relacionadas con este caso que, en su momento, conmocionaron a toda una ciudad, tenían poca relevancia comparadas con las primeras noticias, en las cuales se buscaba a una chica desaparecida. Un análisis comparativo simple demuestra que la primera La noticia publicada por el dia-
rio El Comercio fue compartida 1.388 veces en la red social Facebook; la última noticia fue compartida apenas 20 veces. La indignación colectiva no alcanzó ni siquiera la fase propositiva, según la teoría de generación de la opinión pública escrita por Vincent Price.

\section{a los espacios} públicos

Bauman retoma el tema de lo colectivo y sentencia, refiriendose una vez más a Sidney Cooke, que:

\footnotetext{
"Al carecer de vías de canalización estables, nuestro deseo de asociación tiende a liberarse en explosiones aisladas... y de corta vida, como todas las explosiones. Suele ofrecérsele salida por medio de carnavales de compasión y caridad; a veces a través de estallidos de hostilidad y agresión contra algún recién descubierto enemigo público (es decir, contra alguien a quien la mayoría del público puede reconocer como enemigo privado) (...) El problema de todas estas ocasiones es que se agotan rápidamente: una vez que retornamos nuestras ocupaciones cotidianas, las cosas vuelven, inalteradas, al mismo sitio donde estaban” (Bauman, 1999, p. 11).
} 


\section{Conclusión}

En menos de dos meses, se pasó de la indignación generalizada a la apatía. El caso, que nació y murió en las redes sociales, escasamente llegó a la fase propositiva. Las propuestas esgrimidas por el público conformado alrededor de este asesinato eran inviables, y, seguramente, eso lo sabían quienes se tomaban el tiempo para escribirlas. Nunca se efectuó un debate alrededor de la implementación de la pena de muerte o la cadena perpetua. No se habló a profundidad acerca de las causas y las consecuencias sociales de los crímenes de femicidio. No se habló acerca del rol del Estado en la seguridad ciudadana. El discurso oficial se fundamentó en una visión conservadora, la cual no se rebatió sino que, al contrario, se reafirmó.

$\mathrm{Al}$ comienzo, se pudo observar cómo parte de la ciudadanía reaccionó con virulencia en las redes sociales. Quienes comentaban lo hacían plegados a una "buena causa", no con el fin de buscar soluciones, sino con el objetivo de crear comunidad en torno a fines social y moralmente aceptados. El Gobierno creyó que esos comentarios espontáneos eran una potencial amenaza y actuó con rápidez encausando el caso desde una visión muy conservadora de las relaciones interpersonales, e, incluso, llegó a proponer la Ley Karina del Pozo, proyecto que fue un triste colofón para esta historia, ya que no tuvo cuerpo, ni forma, pero sí un nombre que obedecía a la lógica coyuntural del Gobierno para responder ante una potencial crisis.

Finalmente, las marchas convocadas a través de las redes sociales tuvieron una baja acogida y las noticias del caso giraron alrededor de la pena que recibirían los sospechosos de haber cometido el asesinato. Se puede evidenciar claramente la ausencia de espacios para generar debates públicos acerca de problemas que atañen a la comunidad: no lo fueron las redes sociales; tampoco los medios oficiales y públicos, separados cada vez más el uno del otro, esgrimiendo posturas irreconciliables. Tampoco lo fue el espacio físico en el que se reunieron los familiares a protestar, posiblemente ilusionados con llevar algo de la efervecencia manifestada en las redes sociales a las calles.

El caso muere con la reafirmación de los valores machistas conservadores. Con la creencia esteréotipada de que la mujer tiene "algo que ver" en los delitos que presentan en su contra. Esta afirmación no necesariamente responde a un debate racional efectuado en la esfera pública. Bien lo diría Bauman: "Las creencias no necesitan ser coherentes para ser creíbles” (Bauman, 1999, p. 9).

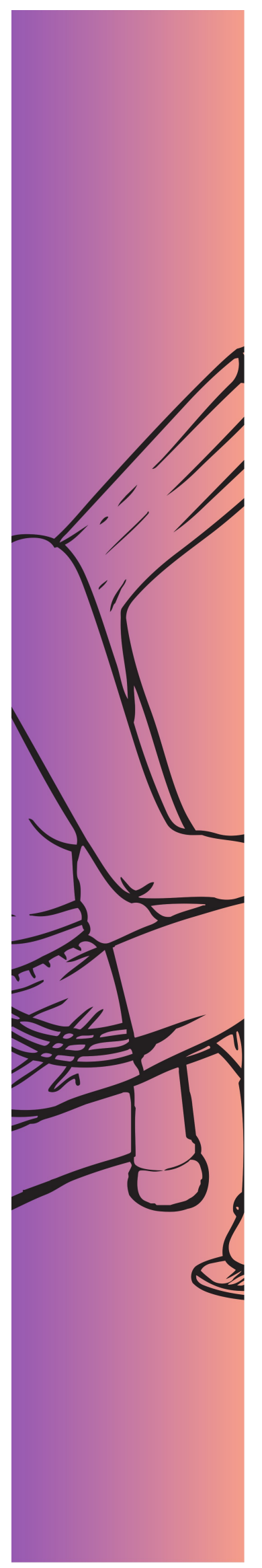


